\title{
EVALUATION OF REGENERATIVE THERAPY USING CELL SHEET THROUGH CEMENTUM PROTEIN-1 EXPRESSION ON MACACA NEMESTRINA
}

\author{
SYANTI WAHYU ASTUTY' ${ }^{1}$, HARI SUNARTO ${ }^{1}$, LISA AMIR ${ }^{2}$, ERIK IDRUS ${ }^{2 *}$ \\ ${ }^{1}$ Department of Periodontology, Faculty of Dentistry, Jakarta, Universitas Indonesia, Indonesia. ${ }^{2}$ Department of Oral Biology, Faculty of \\ Dentistry, Jakarta, Universitas Indonesia, Indonesia. Email: erik.idrus31@ui.ac.id
}

Received: 16 September 2017, Revised and Accepted: 3 October 2017

\section{ABSTRACT}

Objective: The main objective of periodontal therapy is tissue regeneration. Previous studies have identified the potential of mesenchymal stem cells to improve major periodontal defect reconstruction in bone tissue engineering. Cell sheet technology (CST), in which a cell culture is obtained from a material coated with a temperature-sensitive substrate, has been developed for the reconstruction of various tissues, including periodontal tissue. Cementum protein-1 (CEMP-1) is a 50-kDa protein that plays a crucial role in cementogenesis by enhancing the combining of cells formed by cell cementoblast.

Evaluate periodontal tissue regeneration with CST, and the application of chitosan, chitosan cell sheet or arginineglycineaspartic acid (RGD)-modified chitosan cell sheet on Macaca nemestrina one-wall defect model.

Methods: The CEMP-1 was analyzed expression in a sodium dodecyl sulfate polyacrylamide gel electrophoresis (SDS-PAGE) gel electrophoresis assay.

Results: CEMP-1 expression in gingival crevicular fluid was observed using the SDS-PAGE method every week for 3 weeks. Protein band expressions on SDS-PAGE gel were identified at around $50 \mathrm{kDa}$ with different thicknesses between groups. The chitosan, chitosan cell sheet, and RGD-modified chitosan cell sheet groups showed protein bands of CEMP-1 between 50 and $70 \mathrm{kDa}$ at weeks 1,2, and 3; weeks 2 and 3; and weeks 1 and 2, respectively.

Conclusion: Our results demonstrated that the application of chitosan and RGD-modified chitosan cell sheets could enhance bone regeneration, as evidenced by CEMP-1 protein expression levels.

Keywords: Periodontitis, Bone defect, Cell sheet, Cementum protein-1.

(c) 2017 The Authors. Published by Innovare Academic Sciences Pvt Ltd. This is an open access article under the CC BY license (http://creativecommons. org/licenses/by/4. 0/) DOI: http://dx.doi.org/10.22159/ijap.2017.v9s2.26

\section{INTRODUCTION}

Periodontitis is a chronic inflammatory disorder that degrades the integrity of dental support tissues, which include alveolar bones, periodontal ligament, cementum, and gingiva [1]. Periodontal regeneration therapy is an alternative therapy for periodontal disease that restores tissue to its previous form and function. This technique aims to eliminate granulation and necrotic tissue at the bone defect area and thus induce healing. Bone grafts and guided tissue regeneration using membranes are common regenerative materials used in periodontal therapy $[2,3]$.

Regenerative therapy using common regenerative materials is limited to specific types and small- to moderate-sized bone defects. A bone defect with crater defects or a vertical defect with a three-wall bony defect is suitable for the bone grafting procedure [2]. A one-wall bone defect or horizontal bone defect has less healthy cells and a large defect, causing difficulties in the ability of grafts to produce regenerative cells that are similar to or that resemble the lost tissue $[4,5]$. To overcome this limitation, several combinations of regenerative therapies and tissue engineering applications have been studied.

Tissue engineering techniques stimulate the regeneration of damaged but alive tissues using cells, scaffolds, and triggers (signaling factor) [6]. Isolated cells were grown in vitro to obtain a sufficient amount, and then, they were transplanted using a scaffold material to the damaged area. Cell sheet technology (CST) is one of the approaches used in tissue engineering techniques [7]. CST uses special surfaces, known as polymer poly ( $\mathrm{N}$-isopropylacrylamide), that are sensitive to temperature change and are ideal for cell culture [8]. Owing to the structure of a cell sheet, which is fragile, the use of a scaffold could help transplantation to the damaged area.

Chitosan is a chitin, such as the mineralized polysaccharides that form the shell of many sea creatures, which has undergone partial distillation. Chitosan shows biocompatibility and can be degraded enzymatically to form an oligosaccharide that is resorbed quickly [9]. Chitosan can form an insoluble complex with connective tissue molecules such as collagen and glycosaminoglycan to form a three-dimensional porous structure, making it a good choice for a scaffold material in tissue engineering. An ideal scaffold should have the ability to facilitate new bone formation, and the use of chitosan in a Macaca nemestrina study showed that a chitosan scaffold biodegrades after 4 weeks $[4,9,10]$.

The use of chitosan and arginineglycineaspartic acid (RGD) peptide can promote cell attachment; this approach affords advantages such as simple synthesis, minimal cost, low immunogenic activity, relative stability, and tight control of conformation. The peptide structure of RGD enhances the attachment of the chitosan scaffold to the defect area or the root surface of tooth in tissue engineering regenerative therapy [10]. No previous studies have compared the application of a chitosan cell sheet and RGD-modified chitosan cell sheet for treating a large defect such as a one-wall bone defect or horizontal bone defect.

This study evaluates the regeneration outcome of CST application with and without RGD modification through a protein that could define the regeneration process. Cementum protein-1 (CEMP-1) is a specific biomarker for cementum regeneration and the main regulator in cementogenesis [11]. 
It stimulates the attachment of differentiation cells as well as the formation of hydroxyapatite crystals by cementoblast, which is the cell that forms cementum tissue. CEMP-1 expression is limited to cementoblast and progenitor cells, that is, subpopulation cells in the periodontal ligament $[11,12]$.

\section{METHODS}

The study design is a descriptive laboratory experiment on M. nemestrina. This study was approved by Animal Care and Use Committee (Pusat Studi Satwa Primata-IPB) Bogor. A split-mouth design was performed on four regions of the lateral incisor of one M. nemestrina. The alveolar bone was intentionally destroyed in each region to imitate a one-wall defect of chronic periodontitis with an open flap procedure. In each region, a different treatment was applied to the destruction site: Chitosan only as a control group, chitosan cell sheet, and RGD-modified chitosan cell sheet.

The cell sheet was prepared before the flap procedure using ligament periodontal cells extracted from the central incisor. A cell sheet filled with mesenchymal stroma cells was adhered to the chitosan and applied to the defect area. The chitosan group was used as a control in this study. After the treatment, gingival crevicular fluid (GCF) was collected from the gingival sulcus of the lateral incisor using some paper points every week. Paper points filled with GCF were placed in $100 \mu \mathrm{l}$ of $\mathrm{PBS}$ in an Eppendorf tube and stored at $-80^{\circ} \mathrm{C}$ in a refrigerator

A Bradford assay was conducted to determine the protein concentration of each sample. A sodium dodecyl sulfate-polyacrylamide gel electrophoresis assay was performed to detect proteins in the sample based on their molecular weight.

\section{RESULTS}

Fig. 1 shows the results obtained using the electrophoresis gel. The chitosan, chitosan cell sheet, and RGD-modified chitosan cell sheet groups showed a protein band between 50 and $70 \mathrm{kDa}$ in weeks 1, 2, and 3; weeks 2 and 3; and weeks 1 and 2 after application, respectively.
In week 1, a CEMP-1 protein band was seen only in the chitosan group and RGD-modified chitosan cell sheet group, and not in the chitosan cell sheet group.

In week 2, the protein band was seen in the chitosan group and RGDmodified chitosan cell sheet group, and it started to be seen as a thin layer in the chitosan cell sheet group. In week 3 , the protein band was still seen in the chitosan group, and it was seen to become thicker in the chitosan cell sheet group; however, it was no longer seen in the RGDmodified chitosan cell sheet group.

\section{DISCUSSION}

Periodontal regenerative therapy aims to restore oral soft and hard tissues through cells, scaffolds, and/or signaling approaches to functional and esthetic oral tissues. Common periodontal regenerative materials find limited applications when dealing with large bone defects such as a one-wall bone defect. The prognosis for this condition is quite poor owing to the difficulties faced in stabilizing the graft material until regeneration starts [5,13]. An earlier study on M. nemestrina and a human mandible showed the first evidence of improved bone regeneration when using chitosan as a scaffold $[4,9]$. Furthermore, the use of ligament periodontal cell sheets was found to promote regeneration in an animal study $[14,15]$. The difficulties faced in cell sheet application owing to its fragile structure could be overcome using a scaffold such as chitosan. To increase its adherence to defect areas or to a root surface, another peptide structure containing RGD was applied to chitosan $[10,16]$. The results obtained in this study show that the application of chitosan, chitosan cell sheet, and RGD-modified chitosan cell sheet can promote regeneration based on the expression of CEMP-1. Cementum-forming cells (cementoblasts) have the primary function of making and secreting the extracellular matrix proteins required for cementum mineralization. The finding that CEMP-1 is synthesized by cementoblast cells and by restricted periodontal ligament cell populations indicated that CEMP-1 may act as a local regulator of cell differentiation and extracellular matrix mineralization. CEMP-1 is a cementum protein that indicates cementoblast action. Its absence in the chitosan cell sheet group was probably caused by a lack of cementoblast cells in the cell sheet taken from the periodontal ligament
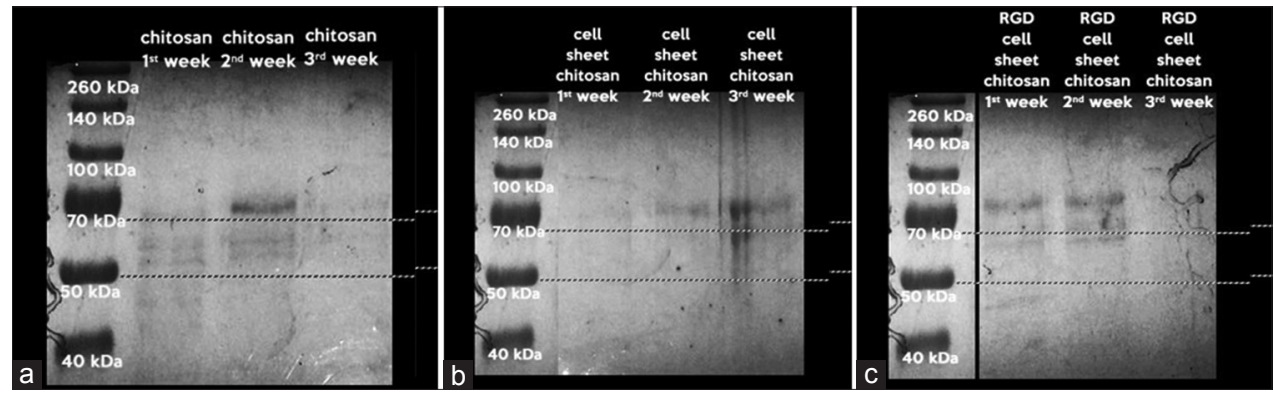

Fig. 1: Differences in cementum protein-1 band from weeks 1 to 3 in (a) chitosan, (b) chitosan cell sheet, and (c) arginineglycineaspartic acid-modified chitosan cell sheet groups
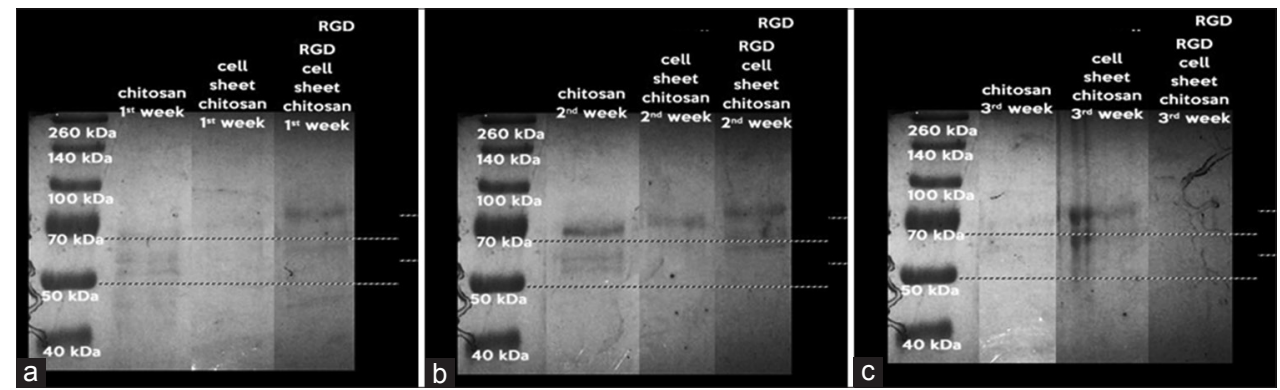

Fig. 2: Differences in cementum protein-1 band between chitosan, chitosan cell sheet, and arginineglycineaspartic acid-modified chitosan cell sheet groups in weeks (a) 1, (b) 2, and (c) 3 
cell. Its appearance in early weeks after application indicated early bone regeneration [12].

\section{CONCLUSION}

A CEMP-1 band could be detected in the chitosan and RGD-modified chitosan cell sheet groups at different appearance times. The application of a cell sheet may enhance healing and bone regeneration.

\section{ACKNOWLEDGMENTS}

We thank Rachel Yuanithea, Yuniarti Soeroso, and Dewi Fatma Suniarti for their support with the experiments, discussion, and technical assistance. This work was supported by a grant from Hibah Publikasi Internasional Terindeks Untuk Tugas Akhir Mahasiswa, Universitas Indonesia, 2016 No.1947/UN2. R12/HKP.05.00/2016.

The publication of this manuscript is supported by Universitas Indonesia.

\section{REFERENCES}

1. Craig R, Kamer A, editors. A Clinician's Guide to Systemic Effects of Periodontal Diseases. New York: Springer; 2016.

2. Sculean A, Nikolidakis D, Nikou G, Ivanovic A, Chapple IL, Stavropoulos A. Biomaterials for promoting periodontal regeneration in human intrabony defects: A systematic review. Periodontol 2000 2015;68:182-216.

3. Lee J, Stavropoulos A, Susin C, Wikesjö UM. Periodontal regeneration: Focus on growth and differentiation factors. Dent Clin North Am 2010;54:93-111.

4. Bachtiar EW, Amir LR, Suhardi P, Abas B. Scaffold degradation during bone tissue reconstruction in Macaca nemestrina mandible. Interv Med Appl Sci 2016;8:77-81

5. Tsumanuma Y, Iwata T, Kinoshita A, Washio K, Yoshida T, Yamada A, et al. Allogeneic transplantation of periodontal ligament-derived multipotent mesenchymal stromal cell sheets in canine critical-size supra-alveolar periodontal defect model. Biores Open Access 2016;5:22-36

6. Ivanovski S, Vaquette C, Gronthos S, Hutmacher DW, Bartold PM. Multiphasic scaffolds for periodontal tissue engineering. J Dent Res 2014;93:1212-21.

7. Yang J, Yamato M, Shimizu T, Sekine H, Ohashi K, Kanzaki M, et al. Reconstruction of functional tissues with cell sheet engineering. Biomaterials 2007;28:5033-43.

8. Matsuda N, Shimizu T, Yamato M, Okano T. Tissue engineering based on cell sheet technology. Adv Mater 2007;19:3089-99.

9. Mohammadi R, Amini K. Guided bone regeneration of mandibles using chitosan scaffold seeded with characterized uncultured omental adipose-derived stromal vascular fraction: An animal study. Int J Oral Maxillofac Implants 2015;30:216-22.

10. Tsai W, Chen Y, Liu H. RGD-conjugated crosslinked chitosan scaffolds for culture and osteogenic differentiation of mesenchymal stem cells. J Taiwan Inst Chem Eng 2013;44:1-7.

11. Torii D, Konishi K, Watanabe N, Goto S, Tsutsui T. Cementogenic potential of multipotential mesenchymal stem cells purified from the human periodontal ligament. Odontology 2015;103:27-35.

12. Carmona-Rodríguez B,Alvarez-Pérez MA, NarayananAS,Zeichner-David M, Reyes-Gasga J, Molina-Guarneros J, et al. Human Cementum Protein 1 induces expression of bone and cementum proteins by human gingival fibroblasts. Biochem Biophys Res Commun 2007;358:763-9.

13. Tsumanuma Y, Iwata T, Washio K, Yoshida T, Yamada A, Takagi R, et al. Comparison of different tissue-derived stem cell sheets for periodontal regeneration in a canine 1 -wall defect model. Biomaterials 2011;32:5819-25.

14. Iwata T, Yamato M, Tsuchioka H, Takagi R, Mukobata S, Washio K, et al. Periodontal regeneration with multi-layered periodontal ligamentderived cell sheets in a canine model. Biomaterials 2009;30:2716-23.

15. Akizuki T, Oda S, Komaki M, Tsuchioka H, Kawakatsu N, Kikuchi A, et al. Application of periodontal ligament cell sheet for periodontal regeneration: A pilot study in beagle dogs. J Periodontal Res 2005;40:245-51.

16. Hansson A, Hashom N, Falson F, Rousselle P, Jordan O, Borchard G. In vitro evaluation of an RGD-functionalized chitosan derivative for enhanced cell adhesion. Carbohydr Polym 2012;90:1494-500. 